\title{
BMJ Open Developing patient education to enhance recovery after colorectal surgery through action research: a qualitative study
}

\author{
Fiona Poland, ${ }^{1}$ Nicola Spalding, ${ }^{1}$ Sheila Gregory, ${ }^{1}$ Jane McCulloch, ${ }^{2}$ Kevin Sargen, ${ }^{3}$ \\ Penny Vicary ${ }^{1}$
}

To cite: Poland F, Spalding N, Gregory S, et al. Developing patient education to enhance recovery after colorectal surgery through action research: a qualitative study. BMJ Open 2017;7:e013498. doi:10.1136/ bmjopen-2016-013498

- Additional material is published online only. To view please visit the journal online (http://dx.doi.org/10.1136/10. 1136/bmjopen-2016-013498)

- Prepublication history and additional material is available. To view please visit the journal (http://dx.doi.org/10.1136/ bmjopen-2016-013498).

Received 18 July 2016 Revised 26 February 2017 Accepted 20 March 2017

\section{CrossMark}

${ }^{1}$ School of Health Sciences, University of East Anglia, Norwich, UK

${ }^{2}$ Norfolk and Norwich University Hospital NHS Foundation Trust, Norwich, UK

${ }^{3}$ Chesterfield Royal Hospital, Chesterfield, Calow, Derbyshire, UK

Correspondence to Dr Fiona Poland; f.poland@uea. ac.uk

\section{ABSTRACT}

Objectives To understand the role of preoperative education for patients undergoing colorectal surgery by involving patients, carers and staff in: (1) identifying its perceived value and deficits for enhanced recovery; (2) modifying current education practices to address educational deficits; and (3) evaluating these changes for preparing patients to enhance their recovery.

Design Qualitative study of three cycles of action research using mixed methods within a 24-month naturalistic enquiry to identify, implement and evaluate changes through observations, questionnaires, semistructured longitudinal interviews, focus groups and documentation review.

Setting A UK 1200-bed National Health Service (NHS) hospital providing colorectal surgery in a small city in a rural county.

Participants Ninety-sevenpatients having colorectal surgery, 19 carers and 22 clinical staff.

Results Themes identified were: (1) knowledge and engagement; (2) situated understanding and confidence building; and (3) partnership and proactive involvement in enhancing recovery. All patients articulated needs to prepare mentally and physically to plan for colorectal surgery and rehabilitation. Patients and carers wanted to counter uncertainty about medical procedures: likely bodily changes, recovery timescales and future. They therefore sought as much personalised, relevant information as possible about their disease, planned surgery and recovery. Staff implemented preoperative education to more specifically inform and respond multimodally to individual needs.

Conclusions Patients wanted to be proactively involved in managing their recovery to re-engage with their everyday lives. Preoperative education supported this through developing patients' situated understanding of hospital and bodily processes related to colorectal surgery. Situated understanding was achieved through educational product to give knowledge and processes promoting engagement. Multimodal, comprehensive and timely preoperative education on the whole patient pathway facilitates active engagement. Situated understanding increased patients' confidence to work in partnership with healthcare professionals and proactively self-manage recovery.

\section{Strengths and limitations of this study}

- An action research approach informed by naturalistic enquiry and a longitudinal design helped build a collaborative approach to ascertain patient education best practice in specific, in-depth ways to be transferable beyond local to national settings.

- The action research approach also helped stimulate awareness of unmet patient education needs on the patient pathway beyond surgery.

- A study limitation was the exclusion of non-Englishcompetent participants perhaps omitting their information needs.

\section{INTRODUCTION}

Preoperative education has been found beneficial to patients' recovery from a diverse range of surgery type, with evidence from different healthcare systems worldwide. ${ }^{2}$ A UK study of 2331 patients found most patients wanted as much information as possible about life changes they face. ${ }^{3}$ This includes detailed information regarding their disease and the treatment they will experience to improve their understanding of what to expect when entering hospital, following surgery and postoperative recovery processes.

\section{Enhanced recovery and preoperative patient education}

The concept of enhanced recovery or fasttrack recovery was introduced in the 1990 s as a programme of care interventions that aims to speed up patient recovery from surgery. In the colorectal surgery field, Kahlet contributed to several early papers evidencing the important role of patient education within enhanced recovery after surgery (ERAS) programmes in supporting positive patient and provider outcomes, including reduced stress, increased sense of control, early discharge from hospital, reduced postsurgical 
complications, potential savings in resource use, reduced morbidity, earlier return to normal activities of daily living and increased patient satisfaction. ${ }^{4-8}$ Subsequent findings from meta-analyses of randomised controlled trial (RCT) results ${ }^{910}$ for ERAS have confirmed such patient benefits including with older patients after colorectal surgery. ${ }^{11}$

Recent papers acknowledge that preoperative education contributes to enhanced colorectal recovery. Wainwright and Middleton ${ }^{12}$ draw on Kehlet's ${ }^{13}$ work to describe the goal as "comprehensively promoting the patient as an active participant in their recovery process and rehabilitation'. Grover ${ }^{14}$ also claims ERAS principles as a dramatic advance in perioperative practice in influencing outcomes and acknowledges the important contribution of preadmission counselling in the preoperative phase of managing colorectal surgical patients.

White $e t a l^{7}$ argue for a multidisciplinary and multimodal approach within an intense preoperative patient education programme for colorectal patients, focusing on active patient participation in recovery and rehabilitation processes. A multimodal approach is supported by RCT evidence for cholecystectomy patients. ${ }^{15}$ Other qualitative research from other types of surgery ${ }^{16}$ has highlighted the importance of preoperative education to support realistic expectations, for increasing quality of life and satisfaction with surgery to support enhanced recovery. Preoperative education supports patients' preparations for hospital admission, surgery, postoperative rehabilitation and return home to self-manage their recovery, helping make the future familiar. ${ }^{17}$

Many patients undergoing colorectal surgery are concurrently coming to terms with a cancer diagnosis. Chelf $e a^{18}$ found that patients with breast, prostate, lung and colorectal cancer preferred 'to learn about their illness through interactive, interpersonal communication with their physicians', reinforced by printed information. Patient education within palliative care was more successful when healthcare staff could adapt delivery to the specific contextual needs and preferences of individual patients. ${ }^{19}$

This study aimed to examine the perceived value of patient education for patients undergoing colorectal surgery for cancer as one component of an ERAS multimodal approach, and how changing the education might better support enhanced recovery by supporting patient self-management.

\section{Context}

This research took place over 24 months from 2010- to 2012, within one UK NHS acute trust where most of the 500 patients referred to the colorectal unit each year underwent bowel cancer surgery. Preoperative education was provided in any one of several preoperative clinic appointments but varying with: surgery type, amount of time between clinic appointment and surgery, whether adjuvant chemotherapy was required and which multidisciplinary clinic team member treated the patient. The preoperative education was not delivered in a standard set sequential process across all patients and could include verbal information by the member of staff working with the patient in the clinic, a detailed education booklet, booklets specifically on ileostomy or colostomy, a $15 \mathrm{~min}$ DVD covering preparation for admission through to recovery and a DVD on stoma self-management if appropriate.

The study objectives were to understand the role of preoperative education for patients undergoing colorectal surgery by involving patients, carers and staff in: (1) identifying perceived value and value deficits for enhanced recovery; (2) modifying current education practices to address educational deficits; and (3) evaluating these changes for preparing patients to enhance their recovery. In the UK, NHS Improvement and the Department of Health encourage clinicians and patients to work together to 'develop strategies and practice that can help health professionals to educate and encourage patients on the [enhanced recovery] pathway' ${ }^{20}$ (p. 25). Dunn $e t a l^{21}$ advocate using qualitative research to better understand patients' experiences of colorectal cancer and to facilitate care that matches patients' education needs. Collaborative action research ${ }^{22}$ that involves the democratic participation of clinicians, patients and carers was seen as a particularly useful approach for identifying problems and potential solutions in situated rather than generic terms. Using the combined knowledge and experience of both 'providers' and 'receivers' of patient education the findings could help identify important and specific ways to understand the role of patient education in enhancing recovery.

\section{METHODS}

An action research approach was selected as a way of integrating research and action to inform potential changes to practice, as advocated by Sharp ${ }^{23}$ to improve health service delivery and by Stetler et $a l^{24}$ for clinical care quality.

The research team comprised three university academics (occupational therapist, health sociologist and nurse), two colorectal unit staff (consultant surgeon and colorectal specialist nurse), and one patient representative who had undergone colorectal cancer surgery. The whole research team was involved in all stages of this study's design, implementation and dissemination. Ethical approval for the study was obtained from the regional Research Ethics Committee (see appendix 1).

\section{Procedures}

Meyer's ${ }^{25}$ four-step action research framework of planning, acting, observing and reflecting was used to evaluate existing practice, implement and re-evaluate change deploying mixed methods within a naturalistic enquiry approach. ${ }^{26}$ Patients who met the inclusion criteria were approached verbally and asked if they would like to receive more information about participating in the 


\section{NHS}

\section{Research Team}

Clinicians _ Researchers Patient Representative
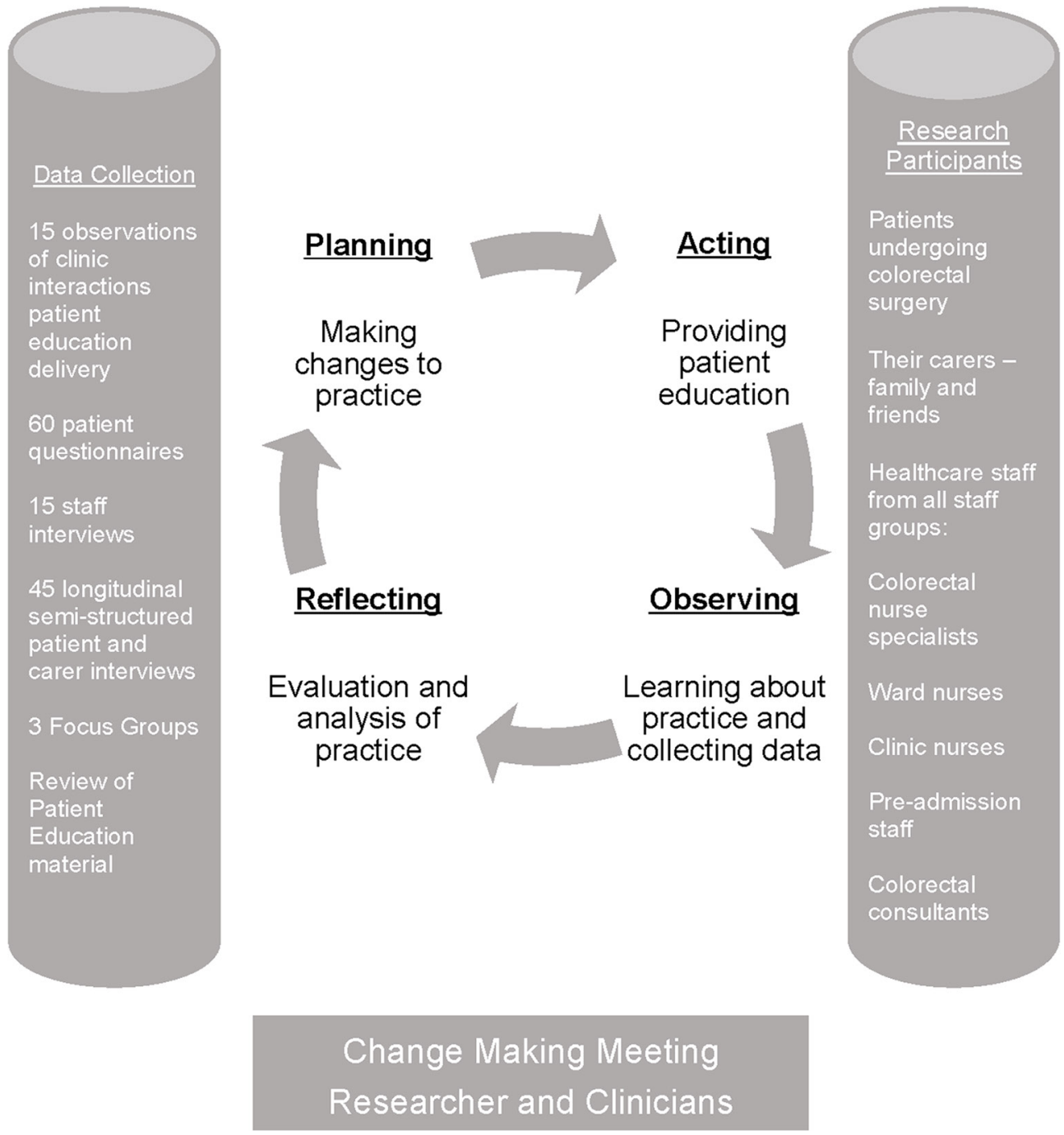

\section{Researcher and Clinicians}

Figure 1 Collaborative action research cycles of data collection.

study. Patient information sheets were posted to patients who expressed such interest, together with separate carer information sheets to enable patients to decide whether to include their carers as study participants. At their subsequent clinic appointment, patients were reapproached by the colorectal specialist nurse to ask if they wanted to participate. Staff were invited to participate and return a response form after receiving a study information sheet.

Multiple methods of data collection, analysis and evaluation were undertaken in three cycles of action research collecting data from different participants in each cycle (figure 1). An academic not involved in the patients' care (author SG) collected all data, after piloting with local patient and public involvement organisation members, within either the NHS Trust premises in a private space or the patient's home. Patients could elect to have a significant other person with them. Patients were allocated to either being observed, being interviewed, completing a questionnaire or taking part in a focus group. Each cycle included: 5 observations of clinic interactions (in which education was embedded) between staff and patients; 20 patient evaluation questionnaires completed immediately after their assessment appointment to gain feedback on the education received; 5 individual semistructured 
staff interviews asking about their views and experiences of patient education provided; 15 longitudinal individual semistructured patient and carer interviews (three per patient, initially presurgery, a second approximately 2 weeks postsurgery and a third, 12 weeks postsurgery); 1 patient and carer focus group at 3 months postsurgery; records of inpatient service interventions; and evaluation of all patient educational material. Interviews and focus groups lasted up to $45 \mathrm{~min}$. Transcripts and portrait vignettes ${ }^{27}$ from each individual interview and observation session were returned to the relevant participant for comment to establish credibility. ${ }^{28}$ Observation session field notes drew on Spradley's nine dimensions ${ }^{29}$ for descriptive review as follows:

1. Space: layout of the physical setting-rooms, outdoor spaces and so on.

2. Actors: the names and relevant details of the people involved.

3. Activities: the various activities of the actors.

4. Objects: physical elements-furniture and so on.

5. Acts: specific individual actions.

6. Events: particular occasions, for example, meetings.

7. Time: the sequence of events.

8. Goals: what actors are attempting to accomplish.

9. Feelings - emotions in particular contexts.

\section{Participants}

People with relevant experience were purposively selected. Participants were patients undergoing colorectal surgery, their carers and healthcare staff from the colorectal unit. Inclusion criteria for patients and carers were:

- patients requiring colorectal surgery or a carer of such a patient;

- aged 18 years or over;

- having mental capacity and English language enabling participation in data collection.

Inclusion criteria for staff were:

- All healthcare professionals of any grade, providing education to patients having colorectal surgery.

While the participant groups were purposively sampled, after consenting they were allocated to data collection methods by convenience to meet target numbers in each cycle. However, the researcher (SG) who allocated to methods was unknown to the patients and not involved in their care.

\section{Analysis}

Interviews and focus groups were audio-recorded and transcribed. Thematic analysis of the transcriptions, observations and questionnaires was undertaken by pairs of the six research team members to provide triangulation and contribute to trustworthiness. Subthemes were then identified within two broad themes: participants' (patients', carers' and healthcare professionals') perceptions of successful practice in delivering patient education and areas identified by participants for improving practice in the content and delivery of patient education. Suggestions for changing the content and delivery of patient education were taken by researchers to a healthcare staff meeting at the end of each Action Research Cycle. Healthcare staff decided which changes to incorporate into practice before starting the next Action Research Cycle. These changes were then evaluated with new groups of patient, carer and healthcare staff participants in subsequent Action Research Cycles (see COREQ for details).

\section{RESULTS}

Participants recruited to the study were 97 patients having colorectal surgery for cancer, 19 carers (always spouse in this case) and 22 clinical staff. Full details on the action research process and change implementation were previously reported. ${ }^{22}$ (See figure 2 summary of research findings and actions). Further analysis of initial codes across the whole dataset are presented to show links between how preoperative education was seen to work or could be improved to enhance recovery. They include illustrating value deficits participants identified as priorities to address. To situate these, some direct quotes from participant interviews, focus groups and questionnaires and in places contextualised by observation field notes, are included to represent all three emergent themes. Identification for quotes have used initials to indicate Action Research Cycle (ARC1, ARC2 or ARC3), type of participant ( $\mathrm{P}=$ patient, $\mathrm{C}=$ Carer and $\mathrm{S}=\mathrm{Staff})$, type of data source $(\mathrm{Q}=$ questionnaire, $\mathrm{I}=$ Interview and $\mathrm{F}=$ focus groups) and the three interviews per patient/carer are referenced accordingly as i, ii or iii.

\section{Theme 1: knowledge and engagement}

Patients and carers described seeking detailed and wideranging information and their views on the value of what they were told and the multiple ways of receiving it:

\section{I think it's good to know exactly what's going to happen, what could happen. (ARC1 Q) \\ It was nice to have the information in writing because there's an awful lot to sort of take in. (ARC2 CI)}

Patients and carers were observed to want to know at preoperative clinic appointments, the specifics of what would happen:

\section{She [Colorectal specialist nurse] had this booklet, and I have still got it now, and she knew exactly where and what would be taken away and everything and what would happen. We must have been half an hour or three quarters of an hour with her, explaining all these things. (ARC1 FP)}

This included medical procedures, scans and colonoscopies, here preparing in minute detail:

I found they didn't give you enough information for the CT scan. When I got there, are you wearing a wired bra?' and I says 'Yes'. 'Well you need to take that off'. Well if they'd told 


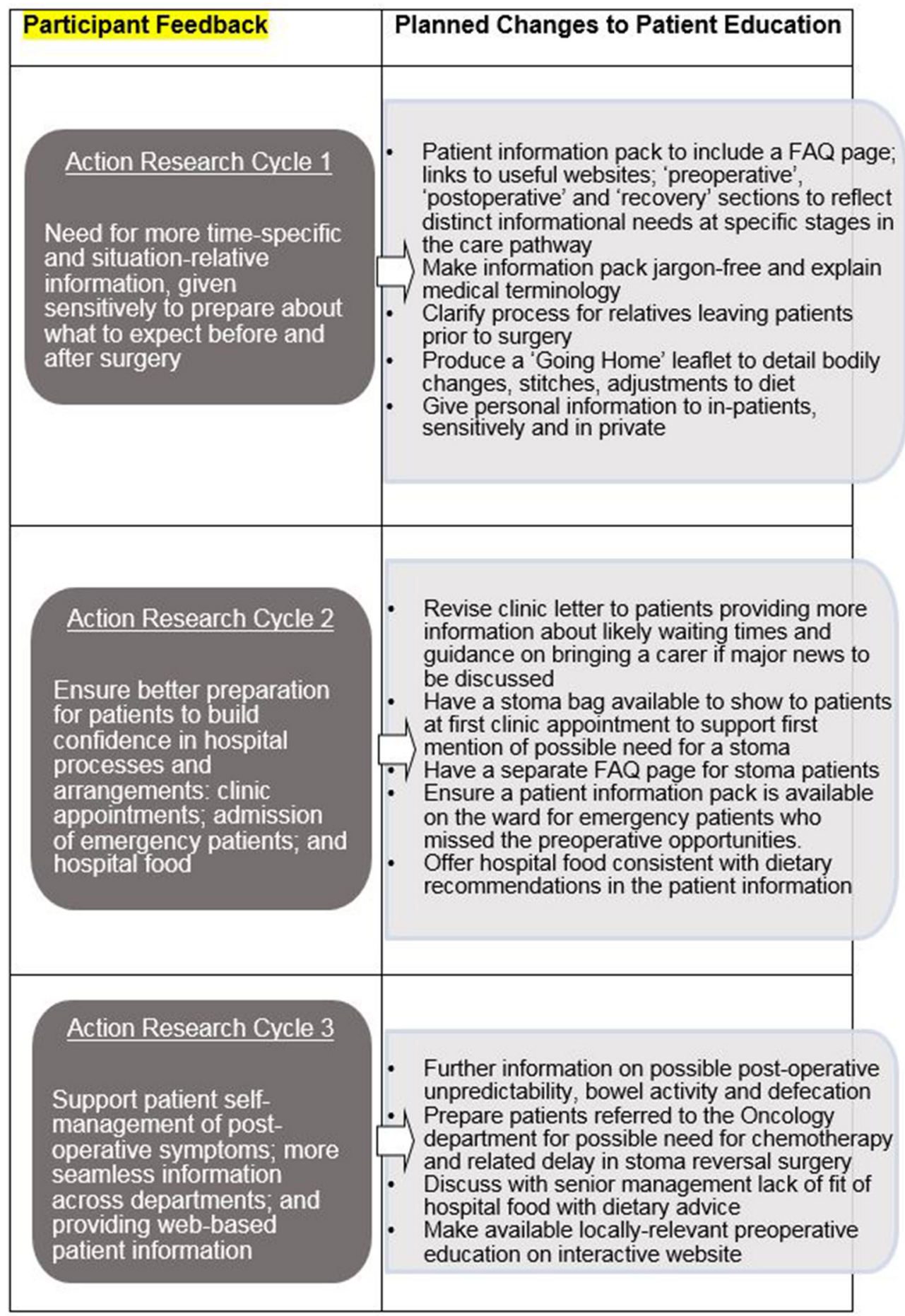

Figure 2 Main research findings and actions.

me that I wouldn't have worn it.... a little thing; you just feel stupid. (ARC3 PI 2i)

A stoma specialist nurse identified the need for more visual representation to inform educational discussion of processes involved, acknowledging patients' individual sensitivities:

Talking about body image change is so very profound and important and sometimes I will start with a diagram. Most patients are willing to look at a diagram and that is the first step. We always ask a patient's permission if it is then $O K$ to look at a photograph. (AR2 SI2)

The value of detailed visual representation was confirmed by some patients' experiences when offered more access to assessment processes:

I mean I know during the colonoscopy that they said 'do you want to watch it on the screen?' and I said 'Yes, of course I do. You know that's my body you are 
pulling about here and I want to know what's going on. (ARC2 PI3ii)

One carer in their focus group suggested having the opportunity of seeing and discussing an actual stoma bag at the first mention of possibly needing one:

if there was a bag or something they could show somebody at the time ...once you're told that you may need a stoma. (ARC1 CF3)

This indicated the usefulness of giving information in a DVD format to all patients as it showed the nurse demonstrating where the stoma bag went on someone's body, using a real stoma bag, if this was not done in clinic. Giving information in these multiple ways was also valued for the potential to reinforce:

There was duplication of information but the reinforcement was good because there is such a lot of information to take in at once. (ARC3 PI3i)

I mean generally speaking, the more information you are given, the better really. I mean it is a very traumatic experience. (ARC1 FP)

Clinicians worried that they should have spent more time to fully discuss and respond to patients' informational needs. Yet patients consistently reported having plenty of time to ask the questions they wanted to:

On more than one occasion we were asked '...can you think of anything else you want to ask?' which is absolutely brilliant. (ARC2 PI5i)

Patients' suggestions for improving practice included being sent information by the hospital team about potential procedures to better prepare patients for discussions during clinic appointments. They also suggested clinic letter revisions to forewarn patients of needing to wait longer than their appointment time or to arrange to have carer support, perhaps if bad news might be given.

A few patients, however, reflected after surgery that they were not prepared enough for the emotional effects of major surgery and its aftermath:

I don't think they've covered a lot of the emotional aspects of it to be honest, do you? (ARC1 PI5iii)

Staff also suggested other ways of addressing patients' information issues such as: speeding up the consenting process by having more personalised consent forms for specific colorectal surgical procedures, providing more onward patient literature especially for non-elective patients, having a 'Frequently Asked Questions' section in the patient information packs and more pictures of a stoma in the stoma booklet. Information given now covers the potential emotional impact for patients, more sources of support and a postsurgery 'Going Home' Leaflet, incorporating more detailed guidelines about typical bodily changes, recovery timescales and diet. Staff also considered practical teaching sessions on stoma management for ward staff to improve consistency of practice in stoma care. Patients saw all of this as giving information tailored to their circumstances:

It has felt like a personalised package of information. (ARC2 PI3i)

This theme highlighted how the information provided patients with knowledge they saw as relevant and, delivered in multiple accessible ways, enabled them to engage with what would happen to them.

\section{Theme 2: situated understanding and confidence building}

Across all data types, patients were seen to want as much personalised, relevant and detailed information as possible about their disease, planned surgery and recovery to counter uncertainty and help regain a sense of life control after becoming dependent on sources of support in hospital that would then be less accessible after discharge:

I must admit when I went home, perhaps because it was that period of time, I did feel as if I had left my lifeline behind me. (ARC1 FP)

Patients and carers needed to prepare mentally and physically to plan their way ahead for their surgery and rehabilitation with increased confidence:

The surgeon explained things to you properly to give you all the information and I think the manner they talk to you gives you the confidence that everything was going to be alright and you will manage. (ARC2 PF)

Staff recognised that patients needed to prepare, and this was observed to be fostered in clinic discussions, as one patient observed:

*I think things were fairly well covered. She was able to fill me in with the bits that I probably hadn't taken in so we could prepare things. She knew what I would be able to do and what she could help me with. (ARC2 PF)

Understanding likely recovery timescales was seen to be vital for regaining confidence. Patients and carers wanted earlier information about the length of hospital stay and postsurgical time to plan for their time at home, including time off work:

My suggestion for a frequently asked question would be about recovery times. How quickly can you get back to work? What about limitations; what you can do and what you can't do; how much you should do in a day? There is a fine dividing line between not doing anything and doing too much. (ARC2 PI5ii)

Planning included breaks and leisure:

Well you see we wanted to book a holiday but that was 'Well shall we?' (ARC1 CF)

One important area for planning was being able to identify what would then be the right foods for them:

...for before surgery and kind of immediately afterwards then you are wanting more information about what you can and can't eat. (ARC1 FP) 
Knowing the incremental stages in their recovery was important for feeling in control of current and future events, including likely bodily changes to understand and anticipate:

... is this normal or is this something to worry about....the unknown is scary...; some of the known things are scary as well but at least when you know you can get it in your head. (ARC1 PI5i)

on the information I was given, it was crucial to my feeling in control, taking responsibility for my own health and well-being. (ARC1 PI1ii)

Each point raised by patients and carers was reported in team meetings and then used for identifying ways develop the education provision.

\section{Theme 3: partnership and proactive involvement in enhancing recovery}

Patients reported their perceptions and appreciation of educational information being given in a variety of ways they could engage and identify with. For example, one patient found the DVD better for ensuring accuracy of interpretation:

It's like the difference between reading a book and using your imagination, and watching a film where you can actually see it. (ARC3 PI5 i)

Patients wanted contextual information to support their ability to manage their own recovery:

A Frequently Asked Question could be how to prepare yourself before surgery and how to enhance your recovery so you can be discharged quickly. That was my main concern. (ARC2 PI3ii)

The practice stoma was brilliant and in hospital I was looking after my own stoma pretty well from the word go. So that helped me go home sooner. (ARC2 PI6ii)

Enhancing patients' understanding of mutual responsibilities reinforced their sense of recovery by building partnerships:

...this is what you can expect and what they expect of you really because I think getting back on your feet is very important and yes, it prepares you for what's going to happen. (ARC1 PI1i)

Being able to select and pace their use of and format of information also supported patients' proactivity.

Postoperative reflections by other patients confirmed the importance of continuing access to such information and educative partnerships at the right time for them:

It is eleven weeks since my surgery now. I did have quite a few problems but they have been extremely helpful at the hospital. I phoned for advice and went up a couple of times to see the stoma nurse so with her help, everything has been resolved wonderfully well. I was anxious and needed some reassurance because of the soreness and not knowing what was happening to my skin. (ARC3 PI6iii)
However, staff continued to recognise that ensuring ever more variety could further improve on this as in redressing the (then) lack of online information:

It's obvious isn't it in this day and age that we should really have a website where everyone gets information? (ARC3 SI1)

Several staff members underlined the need to actively use their team working to bring patients the information they sought:

My aim is to make the hospital experience as stress-free as possible for patients but I am just a $\operatorname{cog}$ in a very big wheel. The biggest contribution I can make is to link with the members of the colorectal cancer team and ensure the patients are supported and fully informed about their diagnosis and treatment. (SI4 ARC 2)

However, many patients also highlighted how consistency of information given is vital to enable them to self-manage with confidence. For instance, where education did not prepare patients before leaving hospital to anticipate changes in bowel processes many experienced concerns:

I wish they'd told me a little bit more about, like I said the diarrhoea and going to the toilet, then I'd have known that was more normal than getting home and sort of worrying about it. (ARC1 PI2iii)

Patients made explicit their need for accurate, comprehensive information to plan to regain independent living:

It was important for me to know everything so I could plan when I went back to work. He knew that was what I had to do and I think because of that they encouraged me more to be independent. (ARC3 focus)

If you take notice of your body and what you have been told, it is common sense really. Then you can get on with your life again. (ARC2 PI5ii)

Where this was not the case, several patients identified specific ways in which this had affected their recovery:

I wish they'd told me a little bit more about, like I said the diarrhoea and going to the toilet, then I'd have known that was more normal than getting home and sort of worrying about it. (ARC1 PI2iii)

These findings therefore made clear connections between patients' proactive involvement in educational processes and partnerships experienced as appropriate and empowering, for their self-managing their own recovery:

*There was no reason why you would go away and not understand what they were talking about. So then it is up to you to do your part to get back to normal. (ARC2 focus group)

\section{DISCUSSION}

The mixed methods action research approach facilitated an in-depth naturalistic exploration of different aspects 


\section{Enhanced Recovery}

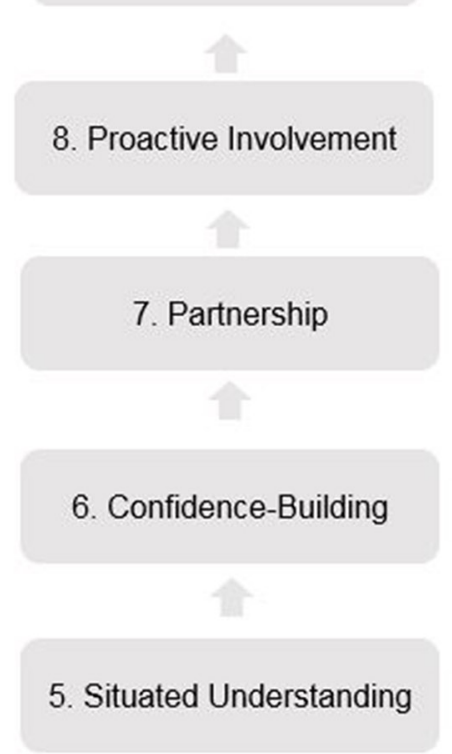

2. Knowledge

1. Product (What)
4. Engagement

\section{Process (How)}

Figure 3 Showing links between preoperative education and enhanced recovery.

of information-giving and how to identify as relevant changes that could encourage proactive involvement of patients as partners in their own recovery, hence contributing to enhanced recovery as identified in previous research. ${ }^{121320}$ Specifically our study identified the importance of patients being able to interactively develop their individual understandings of events within the hospital settings, interventions during and after colorectal surgery and the impact on them ('situated understanding'). Our findings also highlighted the importance of attending to their emotional needs, which Fecher-Jones and Taylor found was often unrecognised, in their 'emotional struggle to regain control of health and well-being' (p. 225). ${ }^{16}$

This action research study identified what patients saw as relevant for enhancing their recovery from surgery, conceptually framed as linked progressive steps presented diagrammatically (see figure 3 ). These steps illustrate that the information provided (the product or educational content) and how this information is delivered (the processes or teaching methods) were necessary foundations to support an enhanced recovery. ${ }^{1}$

1. Product (what): the content of the patient education programme was seen to provide knowledge of what will happen, with whom, involving what and when along the care pathway. All could be seen to provide information-giving opportunities and also challenges for preparing patients to engage with building the knowledge they needed. ${ }^{3}$

2. Knowledge: the information supported patients to build individually relevant knowledge of their condition and consequences for them ${ }^{2}$ across the whole colorectal surgery and recovery process, ${ }^{3}$ so supporting a situated understanding.

3. Process (how): methods of information-sharing with patients and carers were found to reassure ${ }^{30}$ which influenced engagement with their care. ${ }^{2}$ These findings highlighted the importance of attending in specific ways at specific points to delivering education to enable patient engagement, taking account of patients' own (changing) perceptions, not simply as a one-way transfer of information. Written information supported consultations. ${ }^{31} 32$ The importance of the education being multimodal, accurate and consistent, also documented as beneficial elsewhere, ${ }^{33}$ enabled fuller engagement in their surgery preparations and postoperative recovery. 


\section{What is already known on this subject}

- Colorectal surgery confronts patients with sudden bodily changes and health uncertainties.

- Information can enhance recovery

- Preoperative education can provide information for patients to regain some control over how they can manage their own activities such as diet, self-care, energy conservation, leisure and work.

\section{What this study adds}

- Involving colorectal surgery patients, carers and staff in jointly developing preoperative education using collaborative action research offered practice-embedded evidence.

Patients wanted to enhance their recovery in order to reengage with their key activities of daily life.

- Providing multimodal, comprehensive and timely information builds patients' situated understanding and confidence to work in partnership.

- Preoperative education thus enables proactive involvement to support enhanced recovery from surgery.
4. Engagement: active engagement motivated patients and carers to build their picture of meanings the surgery and postoperative care would have for them, again supporting situated understandings. ${ }^{30}$

5. Situated understanding: all of this, therefore, contributed to patients gaining familiarisation with specific colorectal surgery-related future experiences, personnel and environments, as found elsewhere, ${ }^{17}$ to support psychological recovery. A situated understanding enabled patients to build their confidence in moving along the care pathway.

6. Confidence building: such confidence could therefore be seen to be based on patients themselves learning how to use information gained to apply to planning and working in partnership with people involved in their care. The education enabled them to see their potential role in recovery and supported them taking responsibility for this, as documented as significant in ERAS. ${ }^{16} 20$

7. Partnership: patients' gaining the information they needed enabled them to increasingly actively work towards shared goals. Involving carers in successful partnerships also enabled patients and their families to envisage and take active responsibility for their recovery ${ }^{20}$ forming alliances with healthcare staff. Staff appreciating such partnership and having assessed the patients' confidence encouraged patients' active involvement.

8. Proactive involvement: patients were leading more in articulating their potential role in the recovery process, appreciating timescales and defining the outcomes important to them. Thus, they became more active in their education and subsequent recovery process. ${ }^{33}$

9. Enhanced recovery: the components of an optimal patient education process could therefore be seen as supporting patients and staff to collaborate to facilitate timely recovery and optimal outcomes in meeting identified patient needs and in using relevant resources.

Such steps to enhanced recovery conceptualise the recent NHS 'Five Year Forward View', 34 which endorses the patient's organisation National Voices argument for patient empowerment, which argues that recognition by statutory services of patients' own life goals are central to enable personalised care. Support for families, carers and communities can promote well-being and independence as key outcomes of care since patients, their families and carers are often 'experts by experience' in self-managing health.

\section{CONCLUSIONS}

This study identifies the importance of developing patients' situated understanding through preoperative education for supporting enhanced recovery (see table 1). This is seen here to be achieved specifically through educational product to give knowledge and educational process, which both promoted patients' engagement. This was seen to increase patients' confidence to work in partnership with healthcare professionals and so in supporting their proactive involvement to enhance their recovery.

Acknowledgements The authors would like to thank all participants who shared so much of their experiences for this research.

Contributor SG carried out and reported data collection. NS was PI, and $\mathrm{KS}$, FMP and JM were coapplicants and grant holders. All five authors were involved in the initial design, overall study management, analysis planning and interpretation. All authors were involved in the drafting, editing and/or reviewing of this manuscript.

Funding This work was supported by the National Institute for Health Research (NIHR) under its Research for Patient Benefit Programme (grant reference number PB-PG-1207-13321).

Disclaimer The views expressed in thispresentation are those of the author(s) and not necessarily those of the NHS, theNIHR or the Department of Health.

Competing interests None declared.

Ethics approval Norfolk Research Ethics Committee.

Provenance and peer review Not commissioned; externally peer reviewed.

Open Access This is an Open Access article distributed in accordance with the Creative Commons Attribution Non Commercial (CC BY-NC 4.0) license, which permits others to distribute, remix, adapt, build upon this work non-commercially, and license their derivative works on different terms, provided the original work is properly cited and the use is non-commercial. See: http://creativecommons.org/ licenses/by-nc/4.0/

(c) Article author(s) (or their employer(s) unless otherwise stated in the text of the article) 2017. All rights reserved. No commercial use is permitted unless otherwise expressly granted. 


\section{REFERENCES}

1. Gregory S, Poland F, Spalding NJ, et al. Addressing patients colorectal Cancer needs in preoperative education. Health Education 2013;113:502-16.

2. Spalding NJ. Preoperative education: empowering patients with confidence. Int J Ther Rehabil 2004;11:147-53.

3. Jenkins V, Fallowfield L, Saul J. Information needs of patients with Cancer: results from a large study in UK Cancer centres. $\mathrm{Br} J$ Cancer 2001;84:48-51.

4. Kehlet $\mathrm{H}$, Mogensen T. Hospital stay of 2 days after open sigmoidectomy with a multimodal rehabilitation programme. $\mathrm{Br} J$ Surg 1999;86:227-30.

5. Basse L, Hjort Jakobsen D, Billesbølle P, et al. A clinical pathway to accelerate recovery after colonic resection. Ann Surg 2000;232:51-7.

6. Fearon KC, Ljungqvist O, Von Meyenfeldt M, et al. Enhanced recovery after surgery: a consensus review of clinical care for patients undergoing colonic resection. Clin Nutr 2005;24:466-77.

7. White PF, Kehlet H, Neal JM, et al. The role of the anesthesiologist in fast-track surgery: from multimodal analgesia to perioperative medical care. Anesth Analg 2007;104:1380-96.

8. Kehlet H, Wilmore DW. Evidence-based surgical care and the evolution of fast-track surgery. Ann Surg 2008;248:189-98.

9. Eskicioglu C, Forbes SS, Aarts MA, et al. Enhanced recovery after surgery (ERAS) programs for patients having colorectal surgery: a meta-analysis of randomized trials. J Gastrointest Surg 2009;13:2321-9.

10. Varadhan KK, Neal KR, Dejong $\mathrm{CH}$, et al. The enhanced recovery after surgery (ERAS) pathway for patients undergoing Major elective open colorectal surgery: a meta-analysis of randomized controlled trials. Clin Nutr 2010;29:434-40.

11. Bagnall NM, Malietzis $\mathrm{G}$, Kennedy $\mathrm{RH}$, et al. A systematic review of enhanced recovery care after colorectal surgery in elderly patients. Colorectal Dis 2014;16:947-56.

12. Wainwright T, Middleton R. An orthopaedic enhanced recovery pathway. Current Anaesthesia \& Critical Care 2010;21:114-20.

13. Kehlet $\mathrm{H}$. Acute pain control and accelerated postoperative surgical recovery. Surg Clin North Am 1999;79:431-43.

14. Grover M. Enhanced recovery after colorectal surgery. Current Anaesthesia \& Critical Care 2010;21:121-4.

15. de Aguilar-Nascimento JE, Leal FS, Dantas DC, et al. Preoperative education in cholecystectomy in the context of a multimodal protocol of perioperative care: a randomized, controlled trial. World J Surg 2014;38:357-62.

16. Fecher-Jones I, Taylor C. Lived experience, enhanced recovery and laparoscopic colonic resection. Br J Nurs 2015;24:223-8.
17. Spalding NJ. Reducing anxiety by pre-operative education: make the future familiar. Occup Ther Int 2003;10:278-93.

18. Chelf JH, Deshler AM, Thiemann KM, et al. Learning and support preferences of adult patients with Cancer at a comprehensive Cancer center. Oncol Nurs Forum 2002;29:863-7.

19. Kirk P, Kirk I, Kristjanson LJ. What do patients receiving palliative care for cancer and their families want to be told? A canadian and australian qualitative study. BMJ 2004;328:1343-343.

20. Cottle S, Wendy L, Lewis W. Patient involvement in enhanced recovery. Nurs Times 2013;109:24-5.

21. Dunn J, Lynch B, Rinaldis M, et al. Dimensions of quality of life and psychosocial variables most salient to colorectal Cancer patients. Psychooncology 2006;15(1):20-30.

22. Gregory S, Poland F, Spalding NJ, et al. Multidimensional collaboration: reflections on action research in a clinical context. Educational Action Research 2011;19:363-78.

23. Sharp C. The improvement of Public Sector delivery: supporting the evidence based practice through Action Research. Scottish Executive Social Research 2005 http://www.gov.scot/Resource/Doc/ 69582/0018054.pdf.

24. Stetler CB, Legro MW, Wallace CM, et al. The role of formative evaluation in implementation research and the QUERI experience. $J$ Gen Intern Med 2006;21 Suppl 2:S1-S8.

25. Meyer J. Qualitative research in health care. using qualitative methods in health related action research. BMJ 2000;320:178-81.

26. Meyer JE. New paradigm research in practice: the trials and tribulations of action research. J Adv Nurs 1993;18:1066-72.

27. Ely M, Vinz R, Downing $M$, et al. On writing qualitative research: living by words, London. Falmer Press 1997.

28. Lincoln YS, Guba E. Naturalistic enquiry, Beverley Hills, C.A. Sage 1985.

29. Spradley JP. Participant observation. Harcourt Brace: Jovanovich College, 1980.

30. Torbé E, Crawford R, Acheson N. Enhanced recovery programme improving quality. Obstetrics, Gynaecology \& Reproductive Medicine 2014;24:91-3.

31. Walter C, Khair G, Drew P, et al. Patients' perceptions of preoperative enhanced information leaflets for 'Fast-track' colorectal resections: a qualitative study. CARE 2(2). 2008:72-93.

32. Carney L, Jones L, Braddon F, F. Pullyblank, A.M, et al. A colorectal Cancer patient focus group develops an information package. Ann $R$ Coll Surg Engl 2006;88:447-9.

33. Kremer M, Ulrich A, Büchler MW, et al. Fast-track surgery: the Heidelberg experience. Recent Results Cancer Res 2005;165:14-20.

34. Publishers $\mathrm{O}$, England FNHS, England $\mathrm{PH}$, et al. Five year forward view. Monitor 2014 www.england.nhs.uk/wp-content/uploads/2014/ 10/5yfv-web.pdf. 